is provided to the suppliers of the main basic laboratory items to which reference is made throughout the text.

There is no doubt that this work will provide a valuable handbook for all who are concerned with the cultivation of parasites of animals (particularly those of medical and veterinary importance), be this for the purpose of teaching, research or, for example, the commercial production of vaccines and similar biological products, It fills a gap that has long existed between the standard textbooks of laboratory formulae and the vast and scattered literature on this subject by individual research workers. In addition, the authors offer to those less familiar with the topic critical guidance on the best approach to their particular problems. One unfortunate defect is the paucity of information on the cultivation of parasites in tissue culture. Although the matter is given a passing mention in the last section, it is too important an aspect of this field to brush aside. Perhaps Drs 'Taylor and Baker will make this the subject of their next book.

W. Peters

\section{PERSONAL CONSTRUCT THEORY}

\section{The Evaluation of Personal Constructs}

By D. Bannister and J. M. M. Mair. Pp. 232. (Academic Press: London, April, 1968.) 50s.; $\$ 8$.

'ThIs well written, well organized book deals with the theories and methods of the late G. A. Kelly; it presents his theoretical contributions (often in the form of very lengthy quotations) and also goes in considerable detail into empirical studies, many of which have in fact been contributed by the authors and their various associates. The theory of personal constructs may be said to have few more eager and hard-working proselytes than this band of former students from the University of London's Institute of Psychiatry, Maudsley Hospital, and the exemplary statistical rigour of their analyses bears witness to their locus of origin. The theory is described in the first chapter, and linked with the "grid" methods of analysis in the second; later chapters go into considerable detail about both theory and method, compare the repertory grid with the semantic differential, consider reliability and validity of the method and finally deal with some practical and theoretical problems.

As a clear and concise introduction to this field of research the book could hardly be bettered, and it will undoubtedly be used by many psychologists and psychiatrists as their point of departure into these relatively uncharted regions of cognitive structure. Unfortunately they will find that the authors are not only concerned with an objective appraisal of an interesting and promising method; instead, Bannister and Mair seem intent on denigrating all other, alternative approaches to personality study in particular, and psychology in general, and on sug. gesting that there can be only one royal road to advance, namely the theory of personal constructs. This leads them to eschew all reasonable criticism of this theory, and leaves the reader with many unanswered questions; a more modest claim, accompanied by a more open-minded discussion of alternative views, might have won more friends for Kelly's theory.

Kelly's main point seems to be that the dimensions of personality description must not be arbitrarily decided on by the psychologist, but must be derived empirically from the performance of the subjects themselves; it follows from this that different dimensions may (and usually will) be appropriate for different people. In criticism of the traditional method, the authors state that "it is the kind of dimensional structure, within which the psychologist chooses to examine his patient, which governs the type of picture which emerges. His test measures, whether showing stable or variable results, are governed as much by these prior conceptualizations as by features of the person". This is a curious statement; it scems to leave out of account entirely the important fact that these conceptualizations are in fact theories derived from objective data, that they lead to testable predictions, and that unless they are in some ways and to some considerable degree congruent with the "features of the person" such testable predictions would in fact be falsified. We might with just as much justification accuse the physicist of "imposing" conceptualizations relating to length, or electric conductivity, or magnetic properties on physical reality, and of being governed in his measurement more by these than by features of physical reality. Such has always been the method of science, and while Bannister and Mair recognize clearly enough the close association between theory and measurement in relation to Kelly's system, they seem unwilling to recognize a similar association in the work of other psychologists. Conceptualizations may be an im. portant characteristic of a person, but they aro not the only one, and methods which are reasonably adequate for one feature may be quite inappropriate for others.

This blind spot of the authors becomes almost ludicrously clear when we read a sentence like this: "Anxiety loses its physiological trappings and is seen as a structural limitation with a person's construct system; the awareness that one's constructs, as so far elaborated, are inadequate to deal with new events on hand". And they go on to quote Kelly: "Anxiety is the recognition that the events with which one is confronted lie outside the range of convenience of one's construct system". Finally, they claim as a supreme virtue of Kelly's theory that he "is proposing one psychology (not two psychologies, one of 'cognition' and one of 'affect') with an integral language". No doubt it would be nice if we had such a unification, but it cannot be achieved on a purely verbal plane; no amount of rechristening will eliminate the firm physiological anchoring of anxiety responses in the autonomic system, and the equally firm association of cognitive events with the cortex. It will be seen, as typical of the strategy of Bannister and Mair, that they do not discuss the difficulties introduced into their conceptualization by the knowledge we have of these physiological mechanisms and anatomical structures; all is simply swept away by a sovereign wave of the hand. On all existing theories the autonomic system and the visceral brain are fundamentally and causally linked with the experience of anxiety; to dismiss them as "trappings" is hardly a reasonable or acceptable way of dealing with the difficulties presented to the theory of personal constructs. The same remarks apply to the dismissal of "traits" from personality psychology; there is no reasonable discussion of the large experimental literature, but simply an impatient, purely verbal denunciation of the potential usefulness of such concepts.

All this might be acceptable if personal construct theory had in fact proved its value, either theoretically or practically. But, as the authors themselves clearly recognize, this is not so: "Mainly isolated and unreplicated studies have been carried out, which serve only to illustrate the potential usefulness of grid methods and construct theory ideas, rather than providing confirmation of their value". Bannister and Mair do not seem to stand on too secure a platform from which to dismiss most of modern psychology if this is all they have to point to by way of confirmation; a somewhat more modest claim, and a less wholesale rejection of other approaches, might be more acceptable to orthodox psychologists. Personal construct theory, and the repertory grid method, are useful and potentially valuable contributions; there is no doubt that further work in this field is amply justified. In due course we will no doubt know if this approach helps us to understand personality theoretically, or will give us practical leads on how to cure neurotics, how to rehabilitate prisoners, or how to improve the education of our children. At the moment, there is no proper evidence on any of these points, and until there is we can only accept this new-comer into our midst with many qualifications; shouting his virtues from the housetops will not increase his welcome. H. J. EYSENCK 